|| Print ISSN: 2589-7837 || Online ISSN: 2581-3935 ||

International Journal of Medical Science and Diagnosis Research (IJMSDR)

Available Online at www.ijmsdr.com

NLM (National Library of Medicine ID: 101738824)

Original Research Article

Volume 5, Issue 2; February: 2021; Page No. 01-05

\title{
A SURVEY ON ONCOPLASTIC BREAST SURGERY AWARENESS AND PRACTICE PATTERNS AMONG INDIAN SURGEONS: A CROSS-SECTIONAL STUDY
}

\author{
Dr. Vinayak Mishra ${ }^{1}$, Dr. Rajashri Kelkar ${ }^{2}$, Dr. Aditi Agrawal ${ }^{3}$, Dr. Sakina Matcheswalla ${ }^{4}$ \\ ${ }^{1}$ Urban Health and Training Centre, Bandra(East), Mumbai-08, Maharashtra, India \\ ${ }^{2}$ Assistant Professor of Surgery, Department of General Surgery, Grant Medical College and Sir JJ Group of \\ ${ }^{3}$ Consultant Surgeon, Department of General Surgery, Wockhardt Hospital, Mumbai, Maharashtra, India \\ Hospitals, Mumbai, Maharashtra, India
}

${ }^{4}$ MBBS, Grant Medical College and Sir JJ Group of Hospitals, Mumbai, Maharashtra, India

\section{Conflicts of Interest: Nil}

Corresponding author: Dr. Vinayak Mishra

DOI: https://doi.org/10.32553/ijmsdr.v5i2.748

\begin{abstract}
:
Purpose: To assess the perspective and practice patterns of Indian surgeons concerning OBS and compare urban and rural areas.

Patients and methods: A thirteen-question survey was distributed through the social media platform WhatsApp (WhatsApp Inc, California, US) to various Indian surgical society groups across India from $5^{\text {th }}$ May 2020 to $19^{\text {th }}$ May 2020. The questions focused on the surgeons' experience, surgical management technique of choice in breast cancer patients, acceptance and practice of OBS, knowledge of type 1 and type 2 OBS, and axilla management.

Results: Two hundred ninety surgeons responded to the survey out of about 1000, with a response rate of $29 \%$. $17.99 \%$ of the surgeons $(\mathrm{n}=52)$ practiced in a rural region, while $82.01 \%(\mathrm{n}=237)$ practiced in an urban region. $94.12 \%(\mathrm{n}=272)$ of the surgeons reported awareness about oncoplastic breast surgery (OBS), whereas only $5.88 \%$ $(\mathrm{n}=17)$ were unaware of the existence of this procedure. $62.97 \%(\mathrm{n}=182)$ surgeons offered OBS to their breast cancer patients, while $37.02 \%(n=107)$ did not offer OBS. $49.37 \%$ of surgeons in the urban areas do not perform OBS, whereas $78.85 \%$ do not perform it in the rural regions. It also highlights that the percentage of surgeons performing OBS with a plastic surgeon $(29.41 \%)$ is higher than those who carry out the procedure by themselves $(15.92 \%)$.

Conclusion: Most of the Indian surgeons are aware of OBS. In the rural areas, OBS's rate is minimal due to various reasons such as poverty, illiteracy, inaccessible radiotherapy centers, and the absence of training of surgeons in OBS. Few urban surgeons perform OBS themselves while most of them do it with the help of plastic surgeons. Mastectomy is the most commonly performed surgical intervention for breast cancer in rural regions. The practice of OBS should increase in India to improve the postoperative quality of life of breast cancer patients. Keywords: Oncoplastic Breast Surgery, Mastectomy, Breast-conserving surgery, Indian surgeons, Oncoplasty
\end{abstract}

\section{Introduction:}

Breast cancer is the most common cancer in women in India, and the incidence of breast cancer is rising in India. ${ }^{1}$ According to Globocan 2018 statistics, breast cancer is the most common cancer in India, with $14 \%(162,468)$ of total new cancer cases in that year. It is also the most common cause of cancer-related death in India, causing $11.1 \%$ $(87,090)$ cancer-related deaths. ${ }^{2}$ The incidence of breast cancer is also increasing in India's rural regions, with a higher mortality-to-incidence ratio. ${ }^{3}$ This is probably due to lack of an organized breast cancer screening program, poor access to healthcare, and general apathy towards health problems of women. ${ }^{3}$
Although a higher number of breast cancer patients present at a younger age in India, the number of mastectomies is higher. For many years, mastectomy has been performed as the primary treatment for breast cancer, despite breast conservative surgery (BCS) and oncoplastic breast conservative surgery (OBCS) gaining importance since the last century.

"Oncoplastic breast surgery involves radical excision of tumors while maintaining the natural breast contours." It involves complementing breast-conserving surgery with reduction mammoplasty and mastopexy to get a favorable cosmetic outcome. ${ }^{4}$ Oncoplastic breast surgery (OBS) provides a better cosmetic and aesthetic outcome and allows 
for a wider resection margin. OBS techniques are being used more commonly worldwide, and it has even become the procedure of choice in specific settings. However, in a developing country like India, OBS is in a nascent stage, and its prevalence is increasing, with many centers now providing this option to the patients.

This study aims to assess the perspective of surgeons in India towards OBS using a cross-sectional descriptive study design and to make a comparison of the acceptance of this technique between urban and rural regions.

\section{Material and methods}

An online survey entitled "Approach to Breast Cancer management by surgeons in India" was made using Google Forms (Google Inc, California, US) and circulated through the social media platform WhatsApp on surgical society groups (WhatsApp Inc, California, US) among Indian surgeons from $5^{\text {th }}$ May 2020 to $19^{\text {th }}$ July 2020 . We did not consider the sub-specialties of surgeons. The authors designed the survey questions to understand the knowledge, surgical practice methods for Breast cancer management. The survey was circulated approximately among 1000 surgeons, and 290 surgeons responded.

The survey consisted of 13 questions. Out of 13,3 were focused on the surgeon's experience, years in practice, choice of surgeries. Six questions focused on the knowledge, acceptance, and practice of OBS. The remaining four questions were to see the approach towards the axilla.

The questions were provided in the English language in a multiple-choice question format. The respondents were informed of the survey's objectives. The questionnaire was anonymous, and the respondents' identity was not recorded and could not be linked to their responses. Besides, no incentives were offered.

Statistical analysis of the data was performed in Microsoft Excel 2007 (Microsoft Inc.) using pivot tables, frequency distribution tables, and descriptive figures.

In this article, we focus on nine questions focused on the knowledge, acceptance, and practice of OBS.

\section{Results}

Two-hundred and ninety surgeons responded to the survey. One respondent had to be excluded from further analysis owing to incomplete survey. $17.99 \%$ of the surgeons $(n=52)$ practiced in a rural region, while the remaining $82.01 \%$ $(\mathrm{n}=237)$ practiced in an urban region. 94.12\% $(\mathrm{n}=272)$ surgeons reported awareness about oncoplastic breast surgery (OBS), whereas only $5.88 \%(n=17)$ were not aware of the existence of this procedure.

Table 1 highlights the awareness of surgeons about type I and type II breast oncoplasty. Figure 1 demonstrates that $62.98 \%(\mathrm{n}=180)$ surgeons offered OBS to their breast cancer patients, while $37.02 \%(n=107)$ did not offer OBS.
Figure 2 clearly shows that surgeons with less than 10 years of practice, the younger surgeons, offered OBS more frequently than senior surgeons.

Figure 3 shows the pattern of performance of OBCS in rural and urban regions. Figure 4 displays the type of surgeries offered to patients with breast cancer in rural and urban areas. In rural areas, mastectomy was the commonest surgical procedure offered to patients amounting to $87 \%$ while it was $37 \%$ in urban areas. However, mastectomy with flaps was offered in 6-7\% cases in both the regions.

Table 1: Awareness of Oncoplastic Breast Surgery

\begin{tabular}{|c|c|c|}
\hline \multirow{2}{*}{$\begin{array}{l}\text { Questions about awareness of } \\
\text { Oncoplastic Breast surgery }\end{array}$} & \multicolumn{2}{|c|}{ Number (n) of surgeons (\%) } \\
\hline & $\begin{array}{l}\text { Who } \\
\text { answered } \\
\text { correctly }\end{array}$ & $\begin{array}{l}\text { Who were } \\
\text { unaware or } \\
\text { answered } \\
\text { incorrectly }\end{array}$ \\
\hline $\begin{array}{l}\text { When is Type I breast } \\
\text { oncoplasty done? }\end{array}$ & $166(57.44 \%)$ & $123(42.56 \%)$ \\
\hline $\begin{array}{l}\text { When is Type II breast } \\
\text { oncoplasty done? }\end{array}$ & $114(39.45 \%)$ & $175(60.55 \%)$ \\
\hline
\end{tabular}

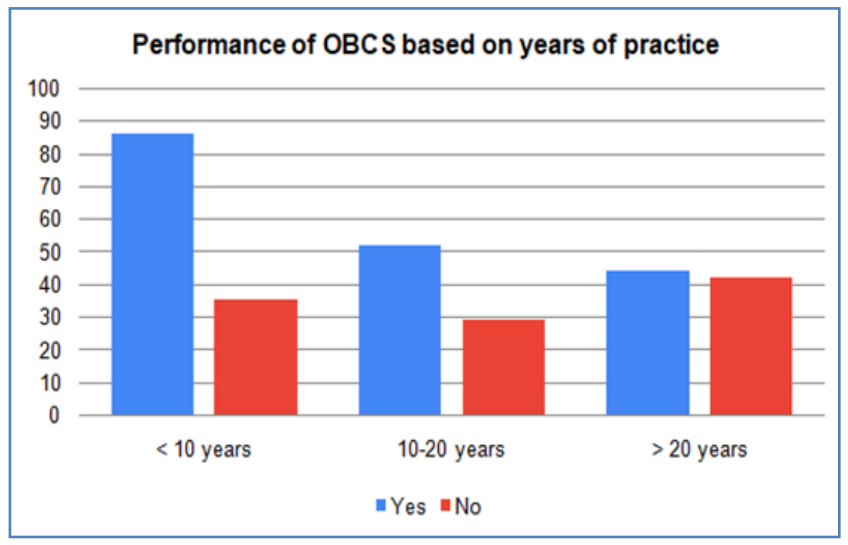

Figure 1: Bar graph showing number of surgeons offering Oncoplastic Breast Conserving surgery (OBCS) in urban and rural areas.

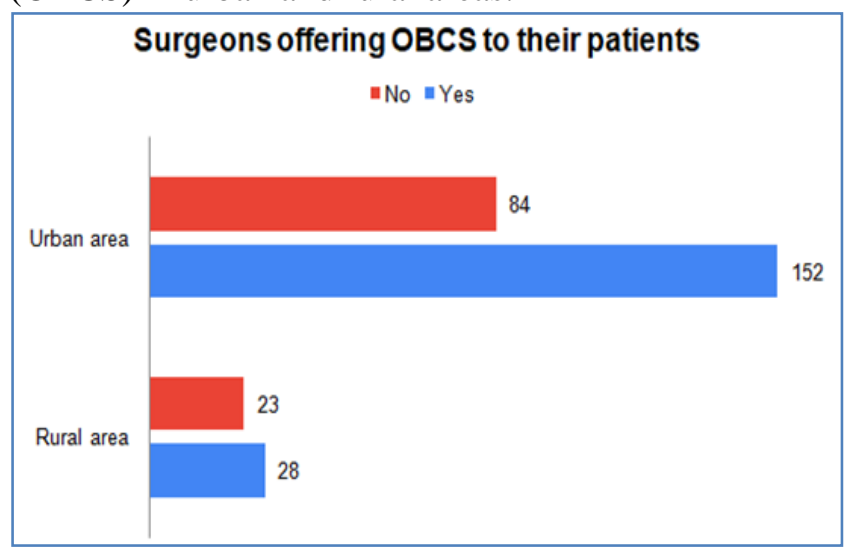

Figure 2: Chart showing number of surgeons performing Oncoplastic Breast Conserving surgery (OBCS) based on their experience. 


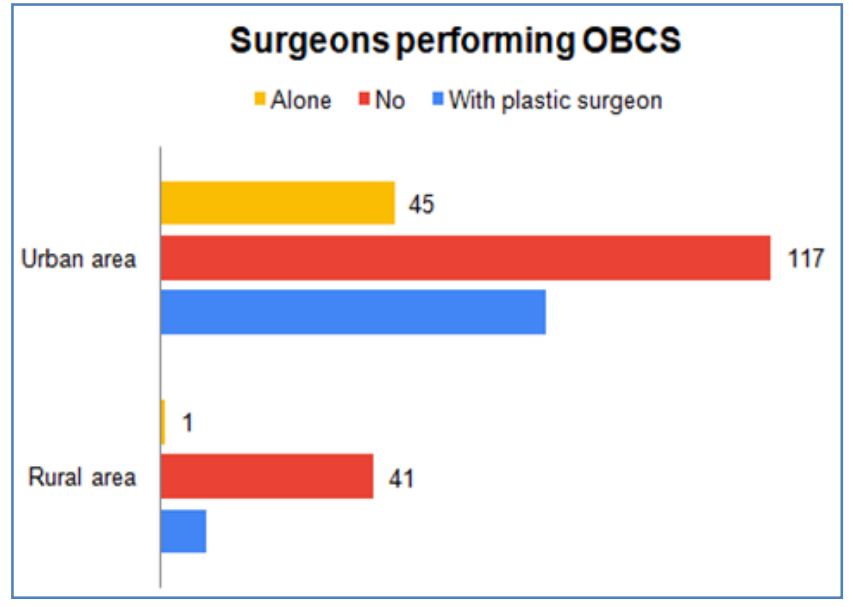

Figure 3: Chart showing number of surgeons performing Oncoplastic Breast Conserving surgery (OBCS) in urban and rural areas.

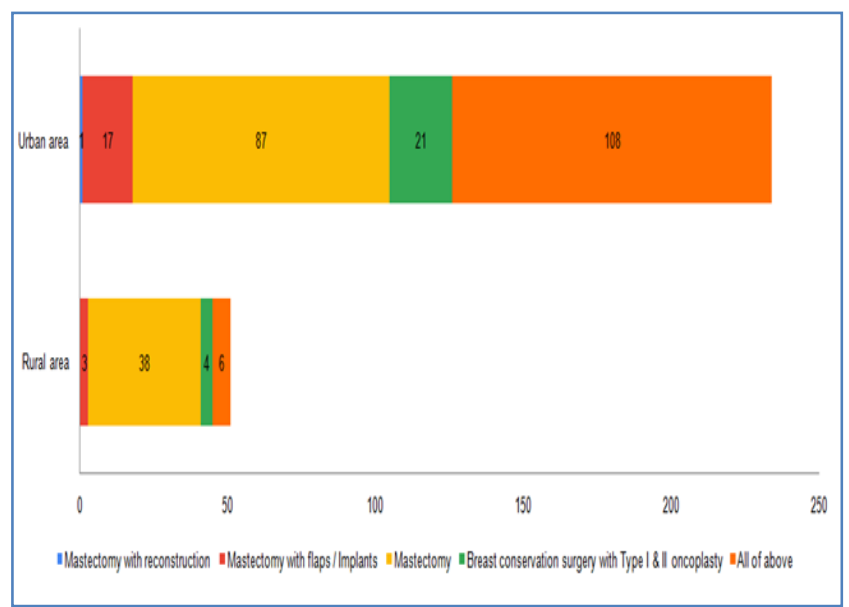

Figure 4: Chart showing the various types of procedures performed for the management of breast cancer in urban and rural areas.

\section{Discussion}

Despite widespread awareness about OBS among Indian surgeons $(94.12 \%)$ in both urban and rural regions, a significant proportion $(37 \%)$ of surgeons did not offer the option of OBCS to their patients, more so in rural areas. About $80 \%$ of breast surgeons in rural areas did not perform OBS, while approximately $50 \%$ didn't perform the procedure in urban areas. However, type 1 and type 2 OBS awareness further lagged, as $42.56 \%$ and $60.55 \%$ of the respondents were not aware of the technique, respectively.

OBS is classified into type 1 and type 2 techniques. Type 1 oncoplastic technique does not require specialized plastic surgical techniques to prevent deformities caused by tumor excisions involving less than $20 \%$ of the breast volume, and it includes reshaping without skin excision, and nipple recentralization. ${ }^{5}$ Type 2 oncoplastic technique is considered when significant volume loss is anticipated, and it is defined as volume displacement and volume replacement techniques. It comprises of tumor excision followed by reshaping the breast parenchyma and reducing the breast skin. ${ }^{5}$

Possible reasons for surgeons not offering OBS to patients are multiple and depend on several factors. In India, a high proportion of patients with breast cancer present at an advanced stage because of various demographic and socioeconomic factors such as low literacy rate, lack of awareness, poor access to healthcare, financial constraints, and lack of an organized breast cancer screening program. ${ }^{6-8}$ In India, there is no universal health care program, and most patients either bear all the expenses themselves or opt for health insurance schemes. Health insurance coverage is just about $2 \%$ of the population. Therefore, many patients who would greatly benefit from this procedure are not able to afford it.

In rural areas, mastectomy constituted $74 \%$ of the surgeries offered for breast cancer management, while breastconserving surgery (BCS) with type I or type II oncoplasty constituted only $8 \%$. This discrepancy can be explained by the higher percentage of patients presenting late with advanced-stage cancer because of the reasons elaborated above and OBS training's unavailability in the rural regions. Besides, there are problems related to accessibility and affordability of adjuvant radiotherapy. With OBS, adjuvant radiotherapy is needed, given as cycles of five days a week for five weeks in India.

Hyperfraction radiotherapy is yet to start in India. Since there is a lack of adequate radiotherapy facilities in India, with less than one radiotherapy machine available per million people, ${ }^{9,10}$ patients from rural areas have to travel to distant cities and stay there for extended durations to avail of radiotherapy treatment. This puts a high financial burden on the patients, and many of them are unable to manage the expenses and thereby opt for mastectomy instead.

Advanced procedures that require breast surgeons and plastic surgeons' combined efforts include tissue flap reconstructions and the use of implants. Emiroglu et al., in his study, found that the general lack of plastic surgeons creates the paradigm for general surgeons to become independent in performing OBS, and they attain the most prominent role in the procedure. ${ }^{11}$ Koppiker et al. also demonstrated that surgeons need to be trained enough to perform both the oncological and cosmetic segments of the surgery themselves, the "one surgeon-dual role" concept. ${ }^{12}$ However, the learning curve is steep, and proper training courses and workshops need to be introduced to address this need.

Breasts are a symbol of femininity, sexuality, and fertility for women; its disfigurement after surgery has an immense impact on women's psychosocial and mental well-being. Therefore, breast cancer surgeries should be modified as far as possible to give an acceptable cosmetic outcome. ${ }^{13}$ OBS improves the final aesthetic results and leads to a higher rate of patient satisfaction. ${ }^{4,14}$ It has also led to alleviation in 
neck and back pain in patients with macromastia. ${ }^{4}$ It also leads to better oncological control as it allows a broader resection margin. ${ }^{4}$ Long-term outcomes of OBS with BCS are superior to standard BCS, as it provides a lower rate of positive resection margins, a reduced rate of re-excision surgeries, and comparable survival rates. ${ }^{14-18}$ This futuristic surgical method has promising results.

Most of Indian surgeons are aware of OBS. In rural areas, OBS's rate is minimal due to various reasons such as cost, inaccessible radiotherapy centers, and absence of training of surgeons in OBS. Few urban surgeons perform OBS themselves while most of them do it with the help of plastic surgeons.

\section{Conclusion}

OBS's rate should rise in India, and it should overcome mastectomy as the most commonly performed surgical intervention for breast cancer in rural regions. Further research into oncoplastic reconstruction training and education is needed to improve the current and future generations of Indian surgeons in this field. Besides, large scale studies comparing the short-term and long-term outcomes of BCS with OBS and BCS alone in the Indian scenario are required. Given the exigency, more oncology centers equipped with radiotherapy facilities should be established with an even distribution between urban and rural areas. Despite the increasing incidence of breast cancer, India can solve this problem by the rational use and distribution of existing resources and the introduction of well-structured OBS training programs.

\section{Disclosure}

The author reports no conflicts of interest in this work.

Ethical Clearance was not required for this survey study as per the Sir JJ Hospital's Ethics committee guidelines.

\section{References}

1. Agrawal A, Tripathi P, Sahu A, Daftary J. Breast Screening Revisited. J Family Med Prim Care [Internet]. 2014 [cited 2020 Jun 12];3(4):340-4. Available from: ttps://www.ncbi.nlm.nih.gov/pmc/ articles/PMC4311339/

2. Globocan 2018: India factsheet [Internet]. India Against Cancer. 2018 [cited 2020 Jun 14]. Available from: http://cancerindia.org.in/globocan-2018-indiafactsheet/

3. Malvia S, Bagadi SA, Dubey US, Saxena S. Epidemiology of breast cancer in Indian women. AsiaPacific Journal of Clinical Oncology [Internet]. 2017 [cited 2020 Jun 12];13(4):289-95. Available from: https://onlinelibrary.wiley.com/doi/abs/10.1111/ajco.1 2661

4. Yazar SK, Altınel D, Serin M, Aksoy Ş, Yazar M. Oncoplastic Breast Conserving Surgery: Aesthetic Satisfaction and Oncological Outcomes. Eur J Breast Health [Internet]. 2018 Jan 1 [cited 2020 Jun
12];14(1):35-8.

Available from: https://www.ncbi.nlm.nih.gov/pmc/articles/PMC5758 061/

5. Clough KB, Kaufman GJ, Nos C, Buccimazza I, Sarfati IM. Improving breast cancer surgery: a classification and quadrant per quadrant atlas for oncoplastic surgery. Ann Surg Oncol. 2010 May;17(5):1375-91.

6. Sathwara JA, Balasubramaniam G, Bobdey SC, Jain A, Saoba S. Sociodemographic factors and late-stage diagnosis of breast cancer in India: A hospital-based study. Indian Journal of Medical and Paediatric Oncology [Internet]. 2017 Jul 1 [cited 2020 Jun 14];38(3):277. Available from: http://www.ijmpo.org /article.asp?issn $=0971$ -

5851 ; year $=2017$; volume $=38$; issue $=3$; spage $=277$; epage $=281 ;$ aulast $=$ Sathwara; type $=0$

7. Thakur NA, Humne AY, Godale LB. Delay in presentation to the hospital and factors affecting it in breast cancer patients attending tertiary care center in Central India. Indian Journal of Cancer [Internet]. 2015 Jan 1 [cited 2020 Jun 14];52(1):102. Available from: http://www.indianjcancer.com/article.asp?issn $=0019-509 \mathrm{X} ;$ year $=2015 ;$ volume $=52 ;$ issue $=1 ;$ spage $=$ 102; epage $=105 ;$ aulast $=$ Thakur $;$ type $=0$

8. Oncoplastic Breast Surgery - Our Experiences in the Breast Clinic, IPGME\&R, Kolkata - PubMed [Internet]. [cited 2020 Jun 9]. Available from: https://pubmed.ncbi.nlm.nih.gov/22693402/?from_ter $\mathrm{m}=\% 28$ Oncoplastic+breast+surgery $\% 5 \mathrm{BTitle} \% 2 \mathrm{FAbs}$ tract $\% 5 \mathrm{D} \% 29+\mathrm{AND}+\% 28$ India\%5BTitle $\% 2 \mathrm{FAbstract}$ $\% 5 \mathrm{D} \% 29 \&$ from_sort $=\&$ from_pos $=2$

9. Munshi A, Ganesh T, Mohanti BK. Radiotherapy in India: History, current scenario and proposed solutions. Indian Journal of Cancer [Internet]. 2019 Oct 1 [cited 2020 Jun 15];56(4):359. Available from: http://www.indianjcancer.com/article.asp?issn=0019509X; year $=2019$; volume $=56$; issue $=4$; spage $=359$; epag $\mathrm{e}=363$; aulast $=$ Munshi; type $=0$

10. Burden of Cancer and Projections for 2016, Indian Scenario: Gaps in the Availability of Radiotherapy Treatment Facilities. Asian Pacific Journal of Cancer Prevention [Internet]. 2008 Apr 1 [cited 2020 Jun 15];9(4):671-7. Available from: http://journal.waocp.org /article_24837.html

11. The Approach of General Surgeons to Oncoplastic and Reconstructive Breast Surgery in Turkey: A Survey of Practice Patterns [Internet]. [cited 2020 Jun 9]. Available from: https://www.ncbi.nlm.nih.gov/pmc/ articles $/ \mathrm{PMC} 4318401 / ? \log \$=$ activity

12. Koppiker CB, Chintamani, Dixit S. Oncoplastic Breast Surgery in India: Thinking Globally, Acting Locally. Indian J Surg [Internet]. 2019 Apr 1 [cited 2020 Jun 12];81(2):103-10. Available from: https://doi.org/10.1007/s12262-019-01890-8

13. Pillarisetti RR, Querci della Rovere G. Oncoplastic Breast Surgery. Indian J Surg [Internet]. 2012 Jun 
[cited 2020 Jun 12];74(3):255-63. Available from: https://www.ncbi.nlm.nih.gov/pmc/articles/PMC3397 $185 /$

14. Losken A, Dugal CS, Styblo TM, Carlson GW. A meta-analysis comparing breast conservation therapy alone to the oncoplastic technique. Ann Plast Surg. 2014 Feb;72(2):145-9.

15. Chen J-Y, Huang Y-J, Zhang L-L, Yang C-Q, Wang K. Comparison of Oncoplastic Breast-Conserving Surgery and Breast-Conserving Surgery Alone: A Meta-Analysis. J Breast Cancer [Internet]. 2018 Sep [cited 2020 Jun 12];21(3):321-9. Available from: https://www.ncbi.nlm.nih.gov/pmc/articles/PMC6158 $154 /$

16. Fitoussi AD, Berry MG, Famà F, Falcou M-C, Curnier A, Couturaud B, et al. Oncoplastic breast surgery for cancer: analysis of 540 consecutive cases [outcomes article]. Plast Reconstr Surg. 2010 Feb;125(2):454-62.

17. Chauhan A, Sharma MM. Evaluation of surgical outcomes following oncoplastic breast surgery in early breast cancer and comparison with conventional breast conservation surgery. Med J Armed Forces India [Internet]. 2016 Jan [cited 2020 Jun 15];72(1):12-8. Available from: https://www.ncbi.nlm.nih.gov/pmc/articles/PMC4723 696/

18. Rietjens M, Urban CA, Rey PC, Mazzarol G, Maisonneuve $\mathrm{P}$, Garusi $\mathrm{C}$, et al. Long-term oncological results of breast conservative treatment with oncoplastic surgery. Breast. 2007 Aug;16 (4):387-95. 